\title{
EVALUACIÓN DE LA CALIDAD DEL AGUA DE LLUViA PARA SU APROVECHAMIENTO Y USO DOMÉSTICO en IBAgué, Tolima, Colombia
}

\author{
Óscar E. Ospina-Zúñiga ${ }^{1}$, Hildebrando Ramírez-Arcila ${ }^{2}$
}

\author{
${ }^{1}$ Docente investigador y coordinador de investigación del programa de Ingeniería Civil \\ 2 Docente investigador y director de Proyección Social del programa de Ingeniería Civil. Correo electrónico: hildebrando.ramirez@campusucc.edu.co \\ Universidad Cooperativa de Colombia, Ibagué, Colombia
}

Recibido: 10 de febrero del 2014. Aprobado: 30 de octubre del 2014

Cómo citar este artículo: 0 . E. Ospina-Zúñiga y H. Ramírez-Arcila, "Evaluación de la calidad del agua de lluvia para su aprovechamiento y uso doméstico en Ibagué, Tolima, Colombia”. Ingeniería Solidaria, vol. 10, n. ${ }^{\circ}$ 17, pp. 125-138, en.-dic., 2014. doi: http://dx.doi.org/10.16925/in.v9i17.812

Resumen. El artículo presenta los resultados del proyecto de investigación "Evaluación de la calidad del agua lluvia para su aprovechamiento y uso doméstico en la ciudad de Ibagué" realizado en la Universidad Cooperativa de Colombia, sede Ibagué, en el 2012. El problema de investigación partió del interés por estudiar el potencial de aprovechamiento del agua de lluvia como fuente alternativa para uso doméstico a partir de la determinación de sus condiciones fisicoquímicas y microbiológicas. La investigación comprendió ocho estaciones de muestreo donde se recogió agua sin contacto con superficie alguna. La caracterización incluyó la medición de turbidez, color aparente, $\mathrm{pH}$, conductividad, temperatura, nitratos, alcalinidad total, cloruros, aluminio, dureza total, hierro total, sulfatos y coliformes totales. Los análisis efectuados demostraron que la composición físico química es susceptible de potabilización al no encontrar niveles temibles de contaminación. Al contrario, la mayoría de los parámetros analizados están dentro de los rangos exigidos para el agua potable exceptuando el pH y turbiedad en algunos puntos de muestreo, permitiendo definir así su potencial aprovechamiento previo proceso de tratamiento convencional que permita remover algunos contaminantes detectados, como coliformes totales, reducción de turbiedad y neutralización del pH por presentar valores bajos como evidencia de agua ligeramente ácida.

Palabras clave: calidad de agua, agua de lluvia, uso doméstico, análisis, Ibagué.

\section{EVALUATION OF RAINWATER QUALITY FOR ITS UTILIZATION and Domestic Use in Ibagué, Tolima, Colombia}

\begin{abstract}
The article presents the results of the research project "Evaluation of Rainwater Quality for its Utilization and Domestic Use in the City of Ibague" ("Evaluación de la calidad del agua lluvia para su aprovechamiento y uso doméstico en la ciudad de Ibagué") carried out at the Ibague campus of the Universidad Cooperativa de Colombia in 2012. The research problem arose from interest in studying the potential for utilization of rainwater as an alternative source for domestic use based on determining its physical-chemical and microbiological conditions. The research involved eight sampling stations from which water was taken without any surface contact. The description included measuring turbidity, apparent color, $\mathrm{pH}$, conductivity, temperature, nitrates, total alkalinity, chlorides, aluminum, total strength, total iron, and total sulfates and coliforms. The analysis showed that its physical-chemical composition is susceptible to purification given the lack of harmful levels of contamination. On the contrary, most of the parameters analyzed are within the required ranges for possible water purification, with the exception of $\mathrm{pH}$ and turbidity at certain sampling points. It would thus be possible to determine the potential utilization of rainwater after a conventional treatment process to remove certain contaminants that were detected, such as total coliforms, reduction of turbidity, and neutralization of the $\mathrm{pH}$ because its low values indicate slightly acidic water.
\end{abstract}

Keywords: water quality, rainwater, domestic use, analysis, Ibagué.

\section{Avaliação da QUALIDAde da Água da CHUVA PARA SEU APROVEITAMENTO E USO DOMÉSTICO na Ibagué, Tolima, Colômbia}

Resumo. Este artigo apresenta os resultados do projeto de pesquisa "Avaliação da qualidade da água da chuva para seu aproveitamento e uso doméstico na cidade de Ibagué", realizado na Universidade Cooperativa da Colômbia, sede Ibagué, em 2012. O problema da pesquisa partiu do interesse por estudar o potencial de aproveitamento da água da chuva como fonte alternativa para uso doméstico a partir da determinação de suas condições físico-químicas e microbiológicas. A pesquisa compreendeu oito estações de amostragem em que se coletou água sem contato com superfície alguma. A caracterização incluiu a medição de turbação, cor aparente, $\mathrm{pH}$, condutividade, temperatura, nitratos, alcalinidade total, cloretos, alumínio, dureza total, ferro total, sulfatos e coliformes totais. As análises efetuadas demonstram que a composição físico-química é suscetível de potabilização ao não encontrar níveis temíveis de contaminação. Ao contrário, a maioria dos parâmetros analisados estão dentro da faixa exigida para água potável, com exceção do pH e turbação em alguns pontos da amostra, o que permite definir assim seu potencial aproveitamento anterior ao processo de tratamento convencional que permita remover alguns contaminantes detectados, como coliformes totais, redução de turbação e neutralização do pH por apresentarem valores baixos como evidência de água ligeiramente ácida.

Palavras-chave: qualidade de água, água da chuva, uso doméstico, análise, Ibagué. 


\section{Introducción}

La actual crisis de agua que aqueja al planeta, manifestada en la pérdida considerable del recurso hídrico, obliga al aprovechamiento de otras fuentes alternativas como el agua de lluvia, que abunda, para el caso de Colombia, en algunos períodos del año. La oferta nacional de recursos hídricos permite el abastecimiento de un alto porcentaje de la población mediante fuentes superficiales y subterráneas, lo cual no significa que el país deba ser ajeno a la situación de crisis de agua que vive el planeta. Por el contrario, es importante preservarla para garantizar el suministro en el futuro, además de buscar fuentes alternativas para uso doméstico y riego como el agua lluvia, cuyo beneficio al consumidor se da directamente en la medida en que es una fuente no tributada a la que toda la población puede acceder, siempre y cuando su uso no represente ningún riesgo.

La calidad de agua de lluvia no se ha estudiado a fondo, se desconocen en varias localidades urbanas sus condiciones físicas, químicas y microbiológicas, que dependen de diversos componentes presentes en el aire por actividades antrópicas y condiciones naturales. Su evaluación permite definir en cierta medida la calidad del aire y los potenciales contaminantes que pueden hacerse presentes en mayor o menor concentración. Por estas razones, la investigación se propuso caracterizar las aguas de lluvias de la ciudad de Ibagué, localizada en la zona central del departamento del Tolima; se estudiaron parámetros físicos, químicos y microbiológicos durante el período 2012, se identificaron puntos de toma de muestra, estableciendo procesos de captura y manejo logístico y, a su vez, se analizaron las muestras a través de los ensayos de laboratorio para identificar la composición fisicoquímica.

\section{Marco teórico}

Dada la marcada dependencia del hombre del recurso hídrico, es un motivo de preocupación la crisis que puede ocurrir con relación a la escasez del agua. Según el Programa de Naciones Unidas para el Desarrollo (PNUD), se prevé que en los próximos años algunas regiones experimentarán un aumento en el estrés y escasez de agua; las zonas más afectadas serán Asia Meridional, África Subsahariana y los Estados Árabes. Además, la publicación Agua para la Vida describe el Mediterráneo Meridional, seguido por Europa, como la zona con mayor escasez de agua en el mundo [2], poniendo en una posición privilegiada a América Latina y el Caribe, Asia Oriental y el Pacífico, que en el futuro continuarán gozando de la suficiente disponibilidad de agua [3]. No obstante, de acuerdo con el Programa de Naciones Unidas para el Medio Ambiente (PNUMA), no toda la población en América Latina tiene acceso al agua potable. En el 2000, el 85\% de la población regional tenía acceso al agua potable y un $79 \%$ estaba cubierto por alguna forma de saneamiento básico [4].

Aunque la disponibilidad del agua dulce es relativamente alta en Colombia, el agua potable no está disponible para todas las regiones del país, según se deduce de las mediciones que se han hecho del Indicador de Riesgo de Calidad del Agua (IRCA), que de acuerdo con el Instituto Nacional de Salud, para el 2009 muestran un panorama donde varios municipios y zonas rurales disponen de agua no óptima para el consumo [5]. Los valores del índice IRCA presentados por la Defensoría del Pueblo, muestran que para el 2009, 248 municipios registraron disponibilidad de agua apta para consumo humano, en contraste con 257 que están en alto riesgo [6]. En la figura 1, se resume el nivel de riesgo de los municipios de Colombia, durante los años 2007, 2008 y 2009.

En el departamento del Tolima, solo el 85\% de los municipios cuentan con un sistema de acueducto y de estos únicamente el $26 \%$ es potable, como lo indican las cifras presentadas por el Ministerio de Ambiente, Vivienda y Desarrollo Territorial [8]. Su capital, Ibagué, no está exenta del problema, a pesar de que el sistema de acueducto es abastecido por tres fuentes hídricas: el río Combeima, la quebrada Cay y la quebrada Chembe. Esta situación ocurre porque en época de lluvia los altos niveles de turbiedad que alcanza su principal fuente, el río Combeima no permiten satisfacer la demanda del recurso para la población. Según el informe presentado por la empresa Ibaguereña de Acueducto y Alcantarillado IBAL S.A. E.S.P., y como se indica en la figura 2, para el período 2009-2012 el río superó en promedio las 33.000 unidades nefelométricas de turbiedad [9], impidiendo el tratamiento. Como consecuencia, fue necesario interrumpir la continuidad en el servicio por algunos periodos.

Según Vanegas, "el río Combeima presenta una tendencia a encañonarse en la parte alta y a conservar taludes bastante fuertes en casi toda su trayectoria. Estas condiciones, asociadas a la composición geológica y al impacto del hombre sobre los sistemas naturales, han hecho que el río presente riesgos de crecidas o avalanchas provocadas por fuertes precipitaciones en su cabecera" [10]. 


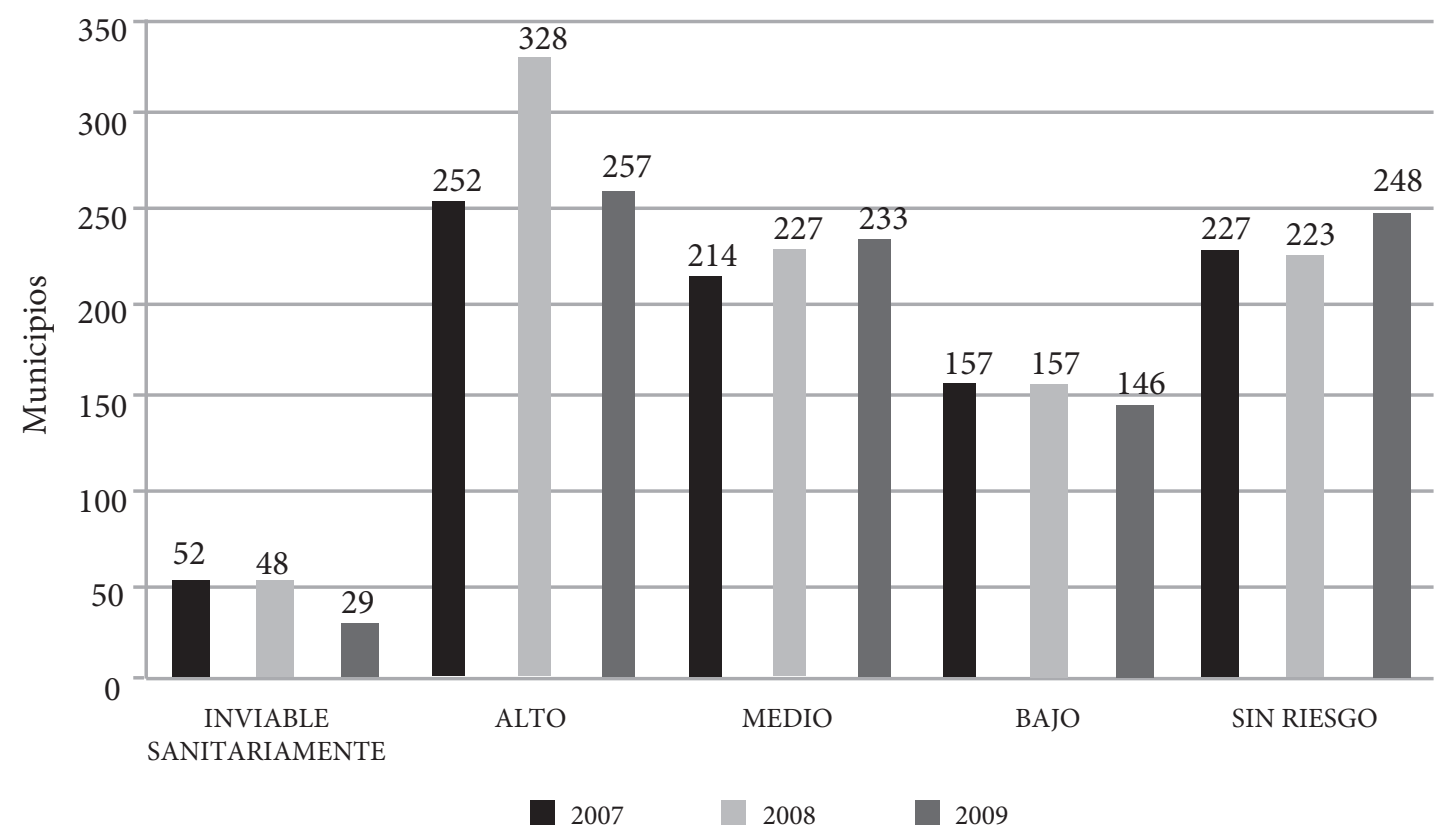

Figura 1. Número de municipios por categoría IRCA

Fuente: [7]

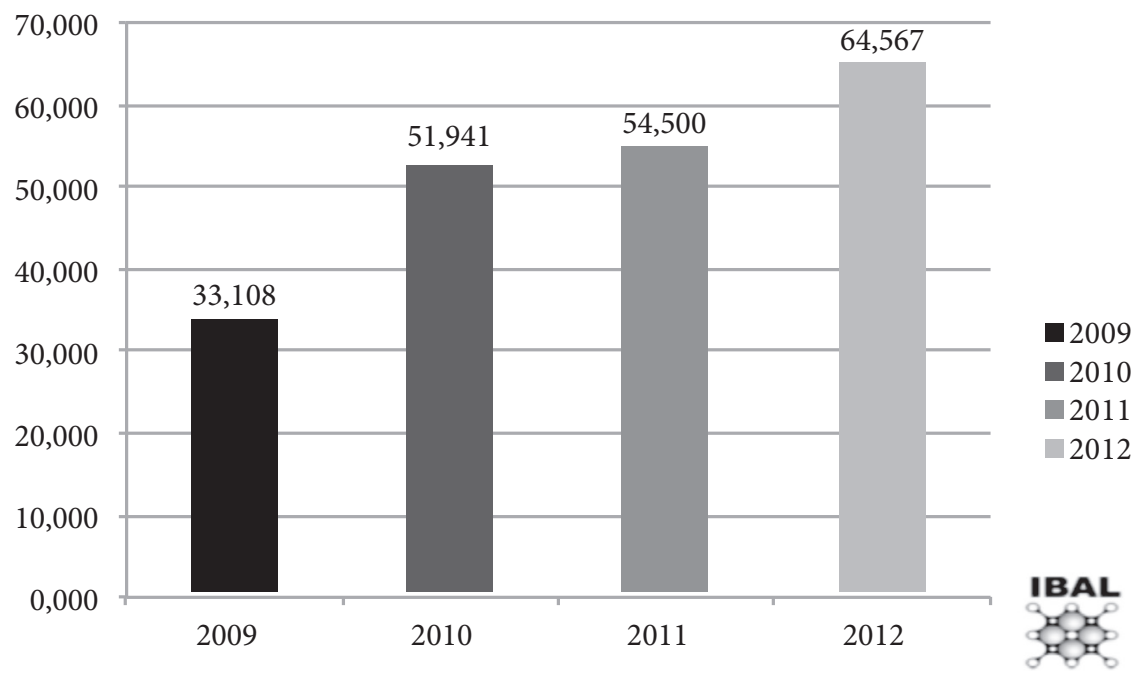

Figura 2. Turbiedad promedio anual del rio Combeima

Fuente: [9]

Los 213 eventos registrados durante el periodo 2009 a 2012 obligaron al cierre de la captación del río Combeima con una duración promedio diaria entre 4,2 a 5,8 horas, según se describe en la figura 3 .

La intensidad de las aguas lluvias en la ciudad es variada debido al comportamiento de los fenómenos meteorológicos en la región, lo que conlleva periodos de baja y alta precipitación, como se describe en la figura 4, de acuerdo con las medias mensuales de las cartas climatológicas del Instituto de Hidrología, Meteorología y Estudios Ambientales IDEAm [11].

La problemática de la caracterización del agua lluvia ha sido motivo de estudio en diferentes países. Para el caso de Chile, la investigación adelantada por Montt et al. sobre la calidad de las aguas lluvias urbanas de Santiago consistió en el monitoreo de las lluvias en doce lugares de la ciudad, tomando muestras desde el sistema de captación del alcantarillado pluvial o al- 


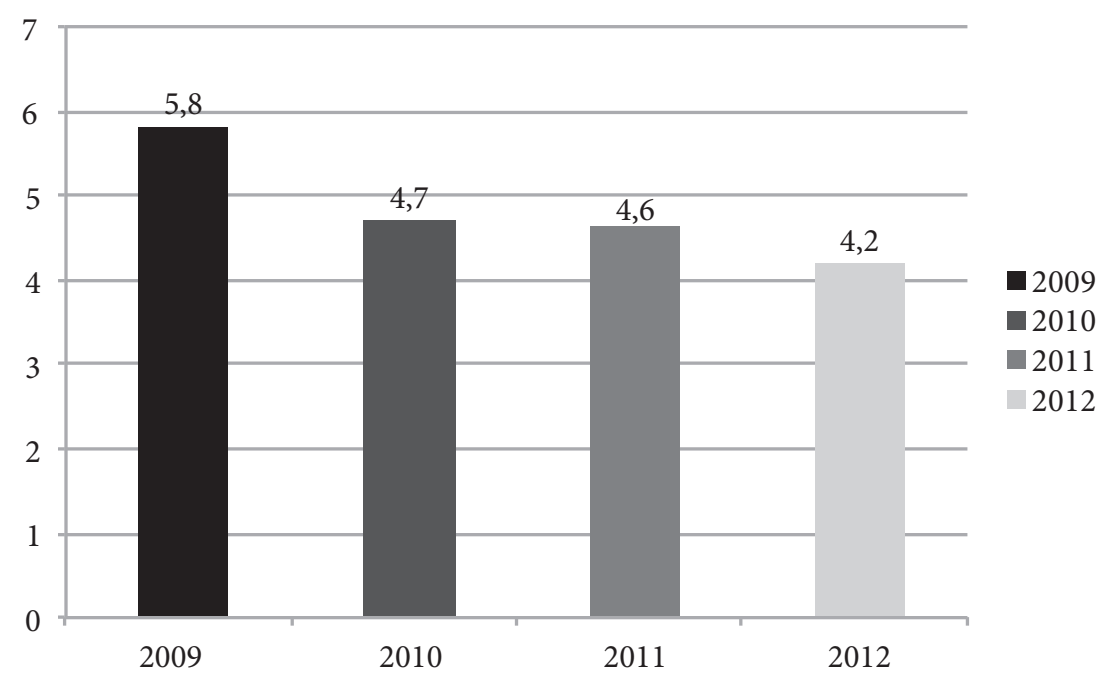

Figura 3. Duración de cierres de la bocatoma del río Combeima durante el período 2009 a 2012

Fuente: [9]
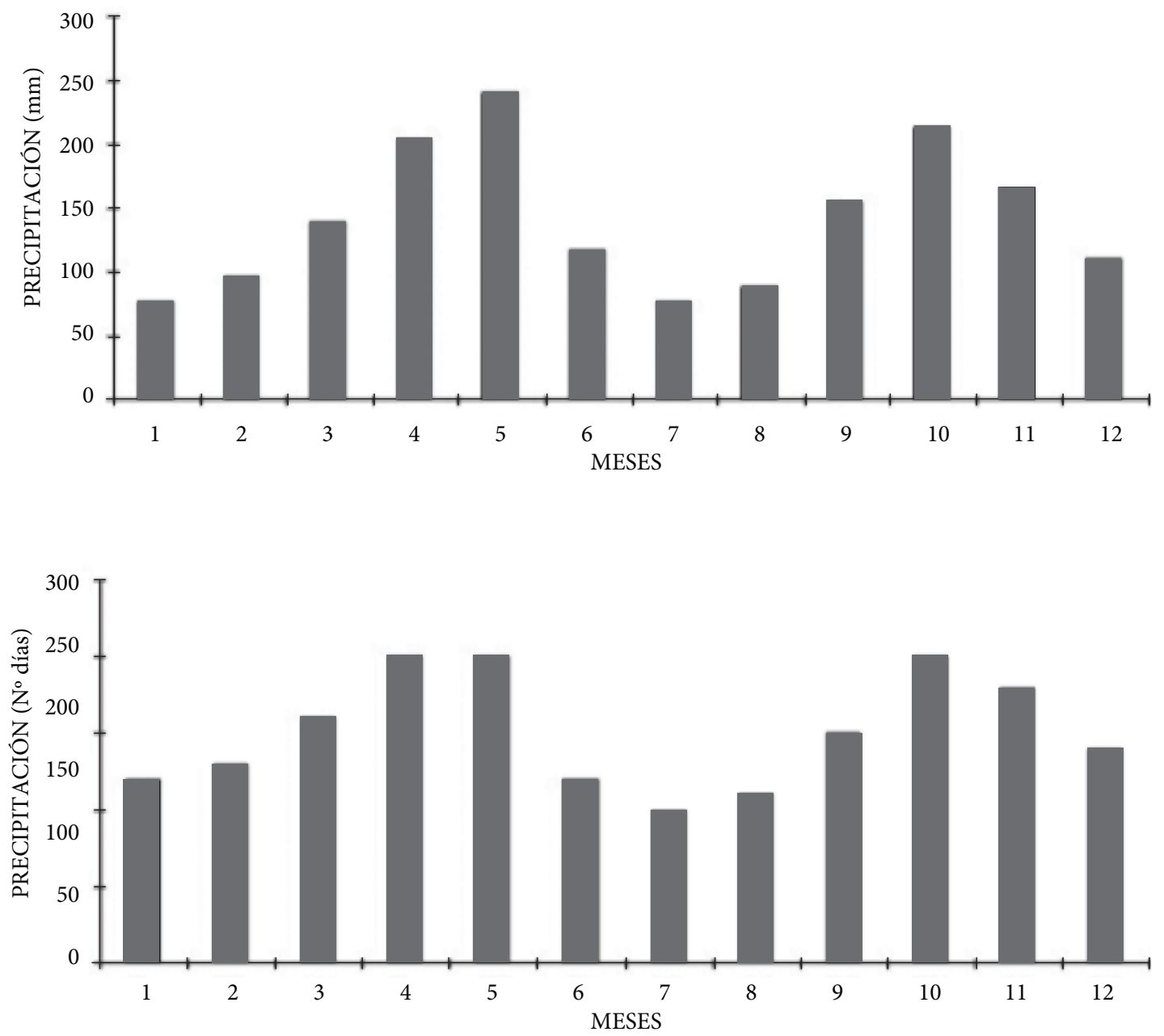

Figura 4. Precipitación en la ciudad de Ibagué de acuerdo con las medias mensuales de las cartas climatológicas Fuente: [12] 
gunas desde el escurrimiento en las cunetas. El trabajo arrojó como resultado que los parámetros aluminio, manganeso, nitrógeno, demanda biológica de oxígeno (Dво) y sólidos suspendidos sobrepasaron persistentemente la norma chilena de emisiones para aguas superficiales [13]. Otro ejemplo es el análisis físicoquímico del agua lluvia en Buenos Aires realizado por Pérez et al., que consistió en ubicar sofisticados instrumentos de muestreo a fin de medir variables como la concentración de material particulado en el ambiente, cuantificar la contaminación además de determinar la composición física y química del agua lluvia. La investigación encontró que los valores de contaminantes presentan alta concentración de nitratos debido a las emisiones de óxidos de nitrógeno [14].

A nivel nacional, Torres et al. realizaron un estudio preliminar de la calidad de la escorrentía pluvial sobre tejados para su posible aprovechamiento en las localidades de Soacha y Kennedy en Bogotá. De su estudio infieren que el agua lluvia no es apta para consumo humano ya que presenta altos niveles de metales como el $\mathrm{pb}, \mathrm{cd}$, zn y cu. Sin embargo, debido a la variabilidad de espacio y tiempo, concluyen que el agua lluvia de escorrentía sobre tejados podría ser adaptada para usos domésticos como vaciado de sanitarios, lavado de pisos y fachadas [1].

Es característico que el pH del agua lluvia sea bajo, pues esta acidez natural se genera cuando los óxidos de azufre y nitrógeno intervienen en la química de la atmosfera y en su equilibrio, causando que disminuya por debajo de 5,6 unidades, mientras que la conductividad aumenta por la presencia de iones. El termino lluvia ácida se refiere a uno de los fenómenos relacionados con el cambio global de la atmosfera, el cual se ha generado a partir de la interacción entre la emisión y formación de gases contaminantes y la dinámica atmosférica. Los principales precursores de la lluvia acida son los óxidos de azufre y los óxidos de nitrógeno, compuestos químicos generados a través de dos vías principales: fuentes antropogénicas, a partir de la que- ma de combustibles fósiles, y fuentes naturales, provenientes de las emisiones volcánicas y fuentes termales, entre otras [16]. La clasificación de la lluvia de acuerdo con el pH se describe en la tabla 1.

Tabla 1. Clasificación del agua lluvia de acuerdo con el pH

\begin{tabular}{|l|l|}
\hline \multicolumn{1}{|c|}{ pH } & \multicolumn{1}{c|}{ Clasificación de la lluvia } \\
\hline $\mathrm{pH}>5,6$ & Lluvia no ácida \\
\hline $4,7<\mathrm{pH}>5,6$ & Lluvia ligeramente ácida \\
\hline $4,3<\mathrm{pH} \leq 4,7$ & Lluvia medianamente ácida \\
\hline $\mathrm{pH} \leq 4,3$ & Lluvia fuertemente ácida \\
\hline
\end{tabular}

Fuente: [16]

El IDEAM se ha encargado desde 1998 de operar el programa de monitoreo del agua lluvia en el país. Su importancia radica en que este es utilizado como un indicador de la incidencia de actividades antrópicas sobre la calidad del aire, pues se logra a partir del seguimiento del pH, conductividad, nitratos y sulfatos, producto del análisis químico de las muestras recolectadas en los sitios de monitoreo seleccionados, teniendo en cuenta la representatividad y confiabilidad de los datos. En esa medida, para Ibagué se presentaron figuras correspondientes a $\mathrm{pH}$ y conductividad para el periodo comprendido entre 2001 y 2006 en la figura 5, y de nitritos en la figura 6 [17].

La determinación del potencial uso doméstico que puede darse al agua se realizó considerando los valores máximos de los contaminantes establecidos en el artículo 38 del Decreto 1594 de 1984, en el que se establecen los criterios de calidad admisibles para la destinación del recurso humano y doméstico que para su potabilización requiere solamente tratamiento convencional [18]. La potabilización del agua lluvia debe cumplir con los requerimientos establecidos en la Resolución 2115 de 2007, donde se señalan las características, instrumentos básicos y frecuencias del sistema de control y vigilancia para la calidad del agua para consumo humano [19]. 


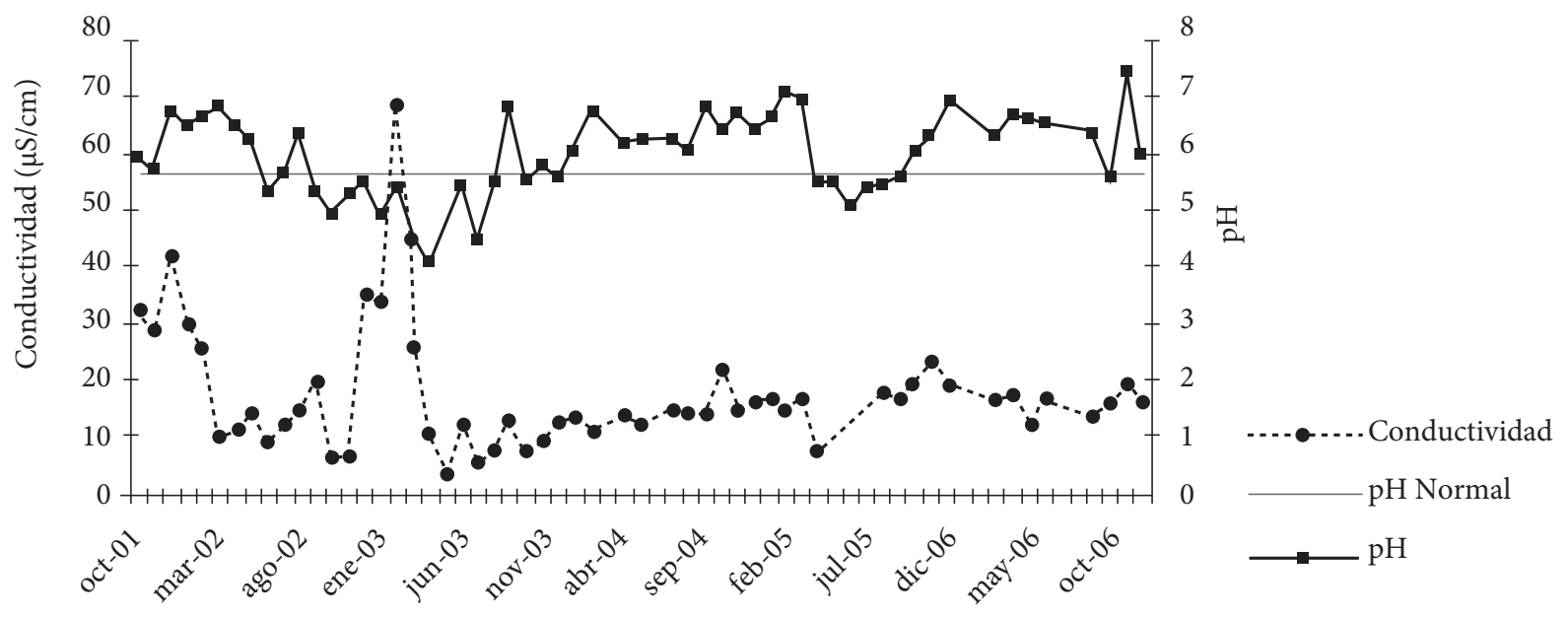

Mes de muestreo

Figura 5. Conductividad y pH de la lluvia de Ibagué entre 2001 y 2006

Fuente: [17]

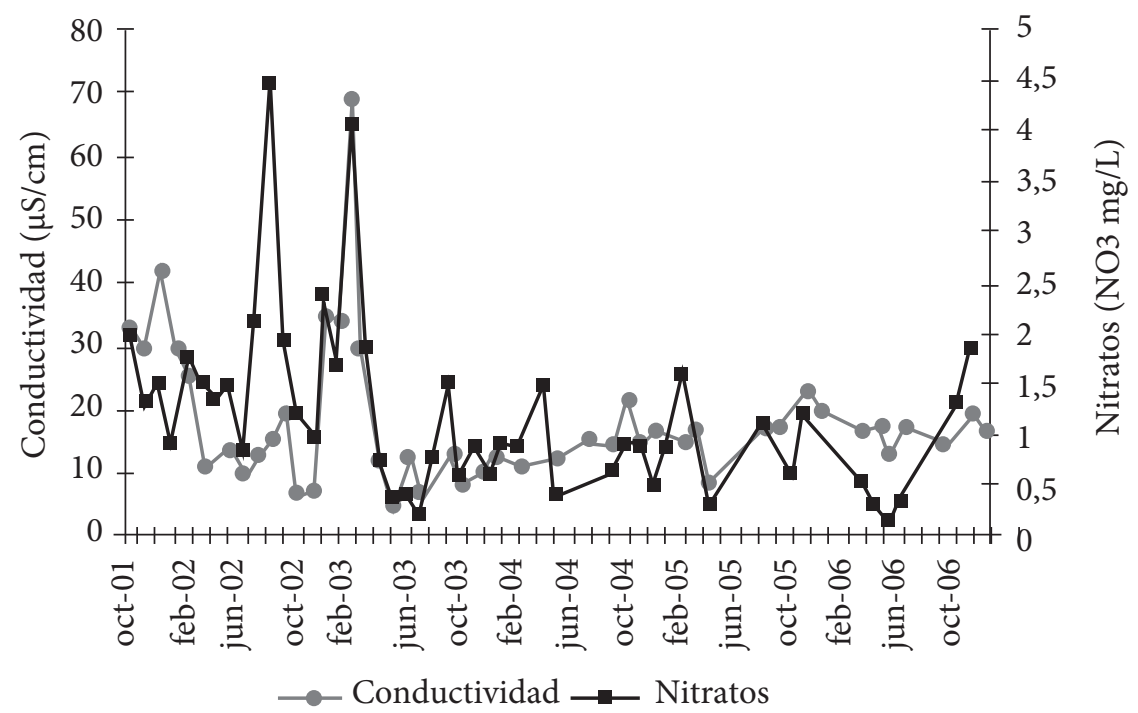

Figura 6. Conductividad y nitratos de la lluvia de Ibagué entre 2001 y 2006

Fuente [17]

\section{Metodología}

La investigación es de tipo exploratorio; se comenzó por hacer la descripción piloto de las características fisicoquímicas y microbiológicas del agua de lluvia analizando parámetros como turbiedad, $\mathrm{pH}$, conductividad, temperatura, color, nitritos, alcalinidad total, cloruros, dureza total, hierro total, sulfatos, aluminio y coliformes totales. Se asumieron estos parámetros pues no existe normativa en Colombia para la calidad del agua de lluvia colectada directamente en el momento de sucederse la misma. El muestreo fue de tipo no probabilístico por lo que los resultados serán solo una aproximación que deja la puerta abierta a futuras investigaciones de tipo descriptivo y explicativo.

El marco geográfico de la investigación se desarrolló en la zona urbana de Ibagué, donde se localizaron 8 puntos de muestreo con sus correspondientes coordenadas planas y geográficas, así como la dirección de su localización, ubicados de forma dispersa, para lograr la mayor representatividad de los resultados en el perímetro urbano de acuerdo con la actividad económica, 
industrial, residencial y minera, especialmente la explotación de rocas para la extracción del mineral denominado feldespato, en la zona norte del perímetro urbano (figuras 7 y 8), con el fin de lograr la mayor cobertura de información sobre la calidad del agua de lluvia; se establecieron los procedimientos logísticos en lo relacionado con la toma, manejo y transporte de las muestras.

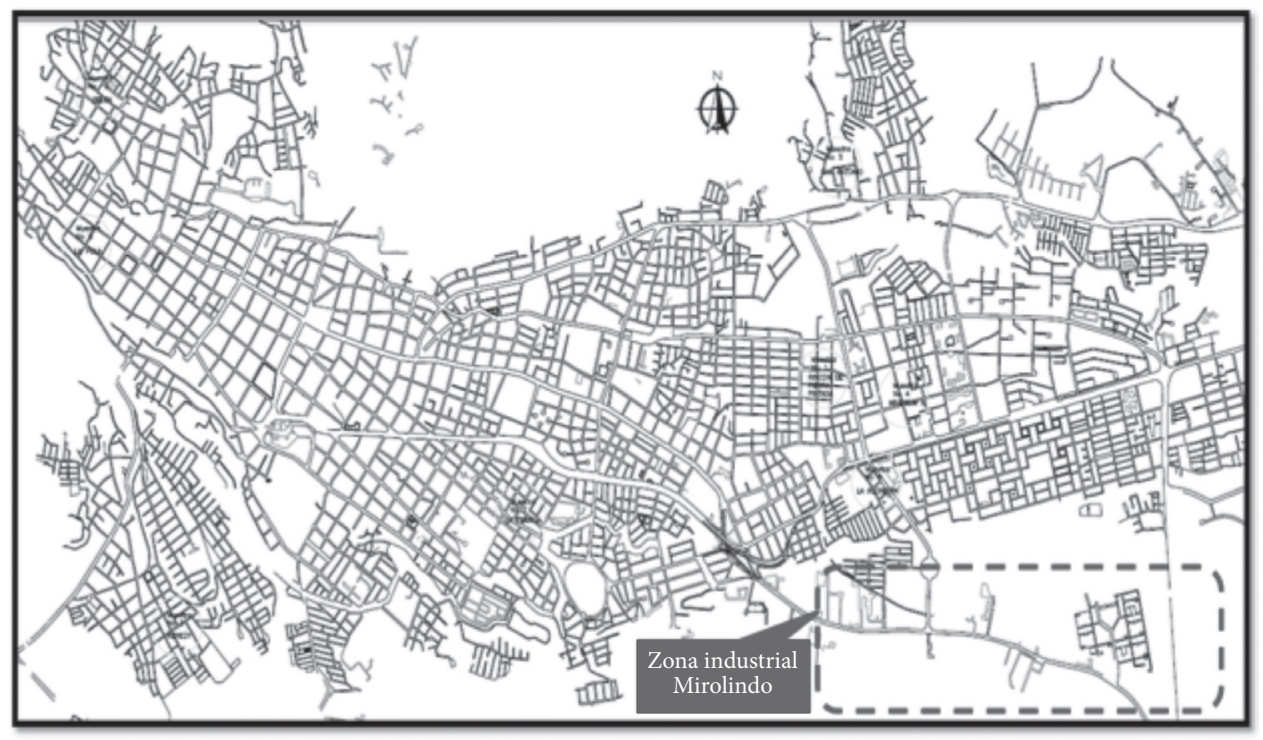

Figura 7. Localización de la zona industrial de Ibagué Fuente: elaboración propia

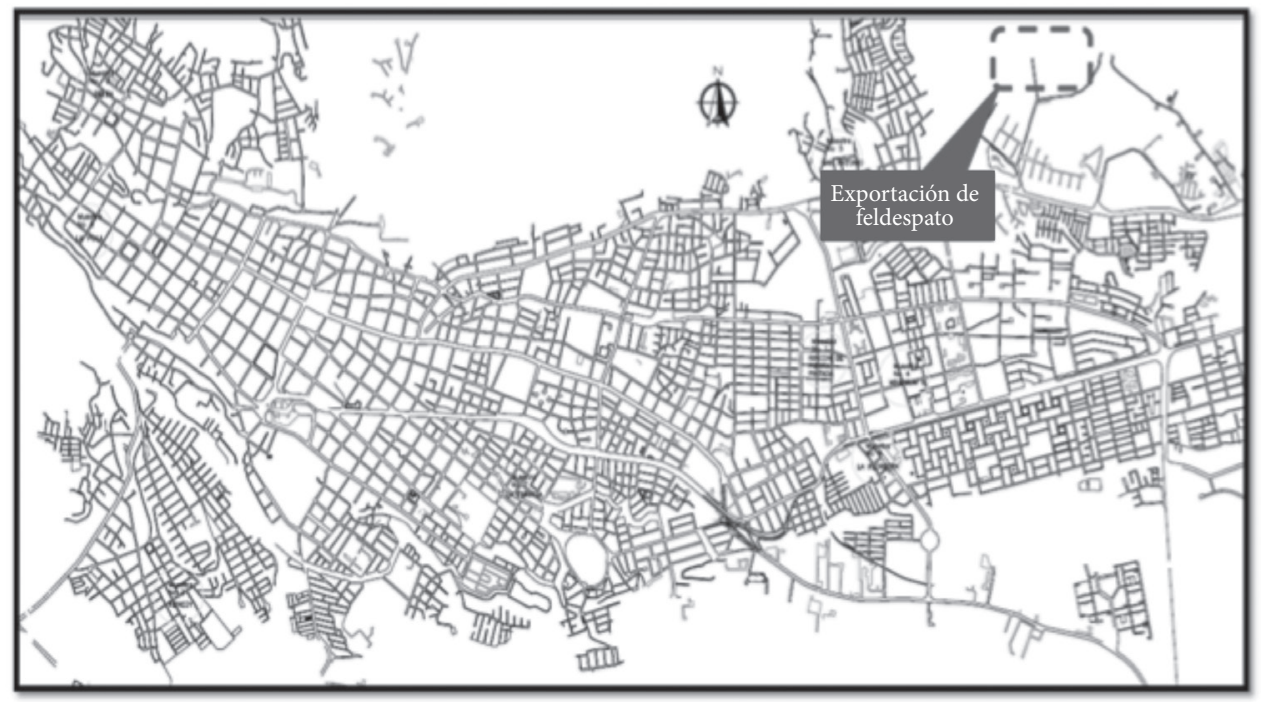

Figura 8. Localización de la zona de explotación de feldespato en Ibagué Fuente: elaboración propia

Las muestras fueron recogidas por los integrantes del equipo con una previa instrucción para su recolección, de manera simultánea, sin entrar en contacto con superficie alguna, utilizando guantes y tapaboca para evitar cualquier riesgo de contaminación en un recipiente de polietileno esterilizado de forma cilíndrica y capacidad de $1000 \mathrm{ml}$. La ubicación de las zonas de muestreo se describen en la tabla 2 [20] y se localizan 
en la figura 9. Las muestras se tomaron durante una lluvia prolongada y uniforme en toda la ciudad (26 de noviembre del 2013, a las 4:00 pm).

Posterior a su recolección, las muestras fueron refrigeradas en una nevera de icopor para luego ser llevadas hasta el laboratorio de Control de Calidad de la Empresa Ibaguereña de Acueducto y Alcantarillado
S.A. E.S.P. Oficial (IBAL), para su evaluación. Los resultados obtenidos de los análisis se plasmaron en tablas a fin de hacer una comparación de los contaminantes respecto a los lugares en que se tomó la muestra, finalmente, se compararon los resultados con la composición de algunas características del agua potable.

Tabla 2. Ubicación de los puntos de muestreo

\begin{tabular}{|c|c|c|c|c|}
\hline PUNTO & $\begin{array}{c}\text { COORDENADAS } \\
\text { PLANAS } \\
\end{array}$ & $\begin{array}{c}\text { COORDENADAS } \\
\text { GEOGRÁFICAS }\end{array}$ & $\begin{array}{l}\text { ALTURA } \\
\text { (m.s.n.m) }\end{array}$ & DIRECCIÓN \\
\hline 1 & $\begin{array}{l}X: 819357.26 \\
\text { Y: } 966962.23 \\
\end{array}$ & $\begin{array}{l}\text { N: } 4^{\circ} 26^{\prime} 21.65^{\prime \prime} \\
\text { O: } 75^{\circ} 12^{\prime} 19.26^{\prime \prime}\end{array}$ & 1140 & Calle 54 No 7 C-19. Barrio Rincón de Piedra Pintada \\
\hline 2 & $\begin{array}{l}\text { X: } 815410.39 \\
\text { Y: } 965705.56\end{array}$ & $\begin{array}{l}\text { N: } 4^{\circ} 25^{\prime} 39.13^{\prime \prime} \\
\text { O: } 75^{\circ} 14^{\prime} 29.20^{\prime \prime}\end{array}$ & 1195 & Calle 24 No 10B-24. Barrio Kennedy \\
\hline 3 & $\begin{array}{l}\text { X: } 819850.02 \\
\text { Y: } 966866.58\end{array}$ & $\begin{array}{l}\text { N: } 4^{\circ} 27^{\prime} 05.19^{\prime \prime} \\
\text { O: } 75^{\circ} 14^{\prime} 03.30^{\prime \prime}\end{array}$ & 1300 & Cra 11 No 3-46. Barrio Belén \\
\hline 4 & $\begin{array}{l}X: 814965.87 \\
\text { Y: } 968411.65\end{array}$ & $\begin{array}{l}\text { N: } 4^{\circ} 26^{\prime} 17.33^{\prime \prime} \\
\text { O: } 75^{\circ} 12^{\prime} 03.30^{\prime \prime}\end{array}$ & 1120 & Cra 7 Calle 60. Conjunto residencial Millenium II \\
\hline 5 & $\begin{array}{l}\text { X: } 819446.94 \\
\text { Y: } 968030.85\end{array}$ & $\begin{array}{l}\text { N: } 4^{\circ} 26^{\prime} 56.42^{\prime \prime} \\
\text { O: } 75^{\circ} 12^{\prime} 15.29^{\prime \prime}\end{array}$ & 1121 & Cra 20 No 60-53. Barrio San Antonio \\
\hline 6 & $\begin{array}{l}\text { X: } 814854.58 \\
\text { Y: } 967614.01\end{array}$ & $\begin{array}{l}\text { N: } 4^{\circ} 26^{\prime} 56.42^{\prime \prime} \\
\text { O: } 75^{\circ} 12^{\prime} 15.29^{\prime \prime}\end{array}$ & 1275 & Cra 1 No 7-23. Barrio la Pola \\
\hline 7 & $\begin{array}{l}\text { X: } 817543.35 \\
\text { Y: } 966272.83\end{array}$ & $\begin{array}{l}\text { N: } 4^{\circ} 26^{\prime} 06.07^{\prime \prime} \\
\text { O: } 75^{\circ} 13^{\prime} 21.49^{\prime \prime}\end{array}$ & 1195 & Cra 4 Calle 32 A 30. Barrio la Francia \\
\hline 8 & $\begin{array}{l}\text { X: } 819688.48 \\
\text { Y: } 966434.09\end{array}$ & $\begin{array}{l}\text { N: } 4^{\circ} 26^{\prime} 02.75^{\prime \prime} \\
\text { O: } 75^{\circ} 12^{\prime} 06.80^{\prime \prime}\end{array}$ & 1132 & Calle 59 No $4^{a}$ - 40. Barrio la Floresta \\
\hline
\end{tabular}

Fuente: elaboración propia

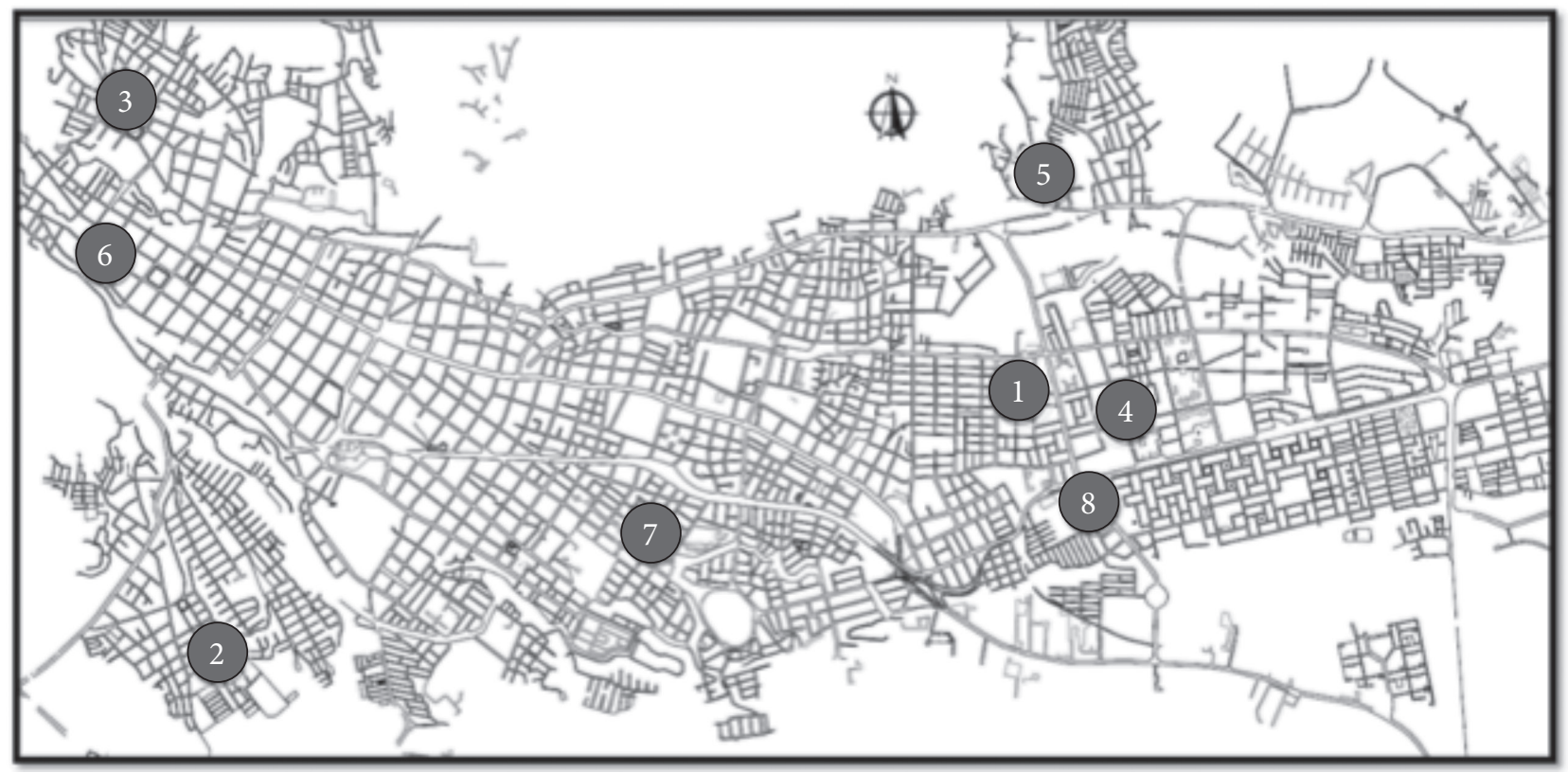

Figura 9. Localización de puntos de muestreo de agua lluvia en Ibagué Fuente: elaboración propia 


\section{Resultados}

De acuerdo con el análisis de la calidad fisica, química y microbiológica del agua lluvia en la ciudad de Ibagué, se evaluó la presencia de turbiedad, pH, conductividad, color, nitritos, alcalinidad total, cloruros, dureza total, hierro total, sulfatos, aluminio y coliformes totales para todas las muestras. La turbiedad, el color aparente у рн se indican en la figura 10; la conductividad, la alcalinidad total y dureza total en la figura 11; cloruros, hierro total y sulfatos en la figura 12; aluminio, nitratos y nitritos en la figura 13, y los coliformes totales en la figura 14. En la tabla 3, se comparan los resultados obtenidos de cada indicador con relación a los criterios de calidad admisibles para la destinación al empleo humano y doméstico con las características para la calidad del agua para consumo.

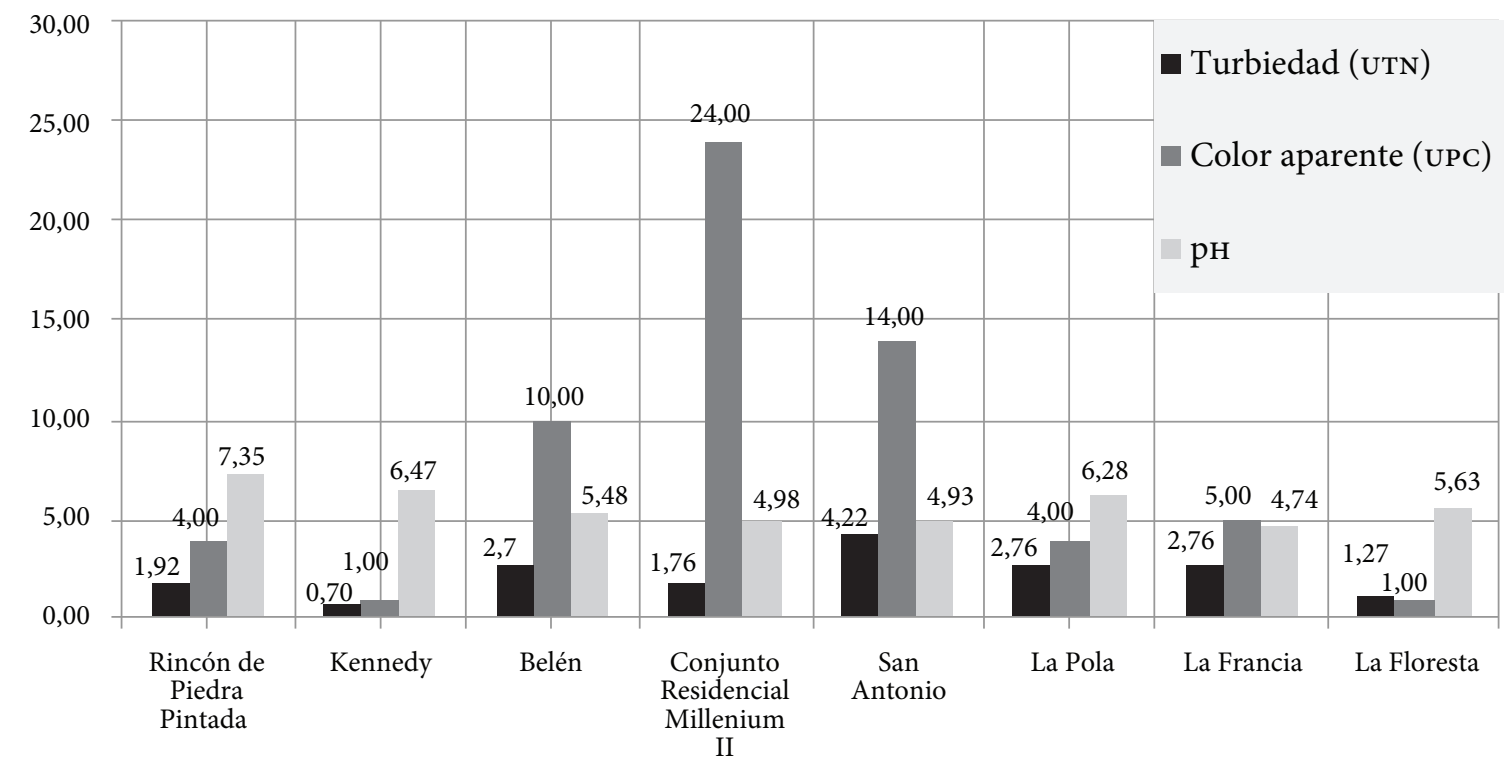

Figura 10. Resultados de turbiedad, color aparente y pH de agua lluvia en 8 puntos de muestreo de Ibagué Fuente: elaboración propia

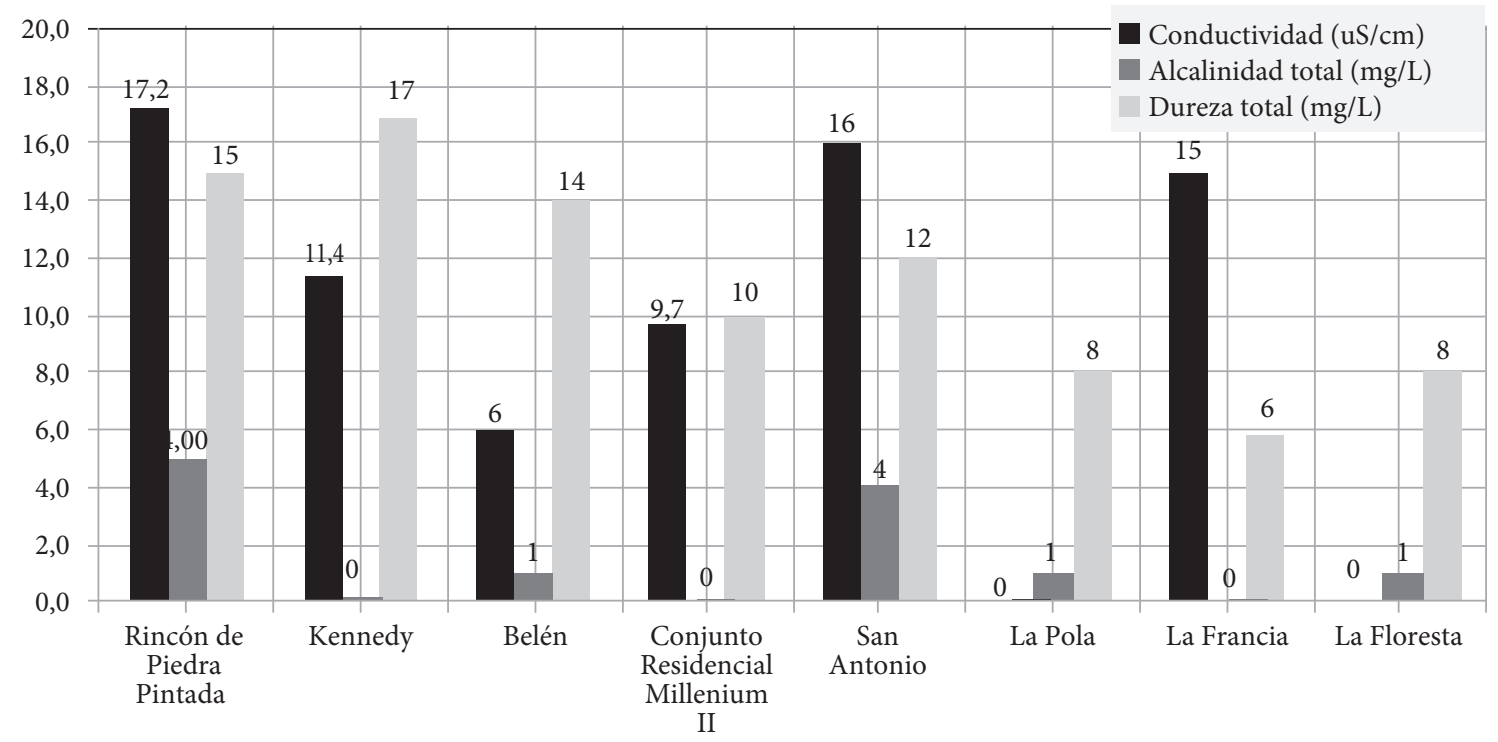

Figura 11. Resultados de conductividad, alcalinidad total y dureza total de agua lluvia en 8 puntos de muestreo de Ibagué Fuente: elaboración propia 


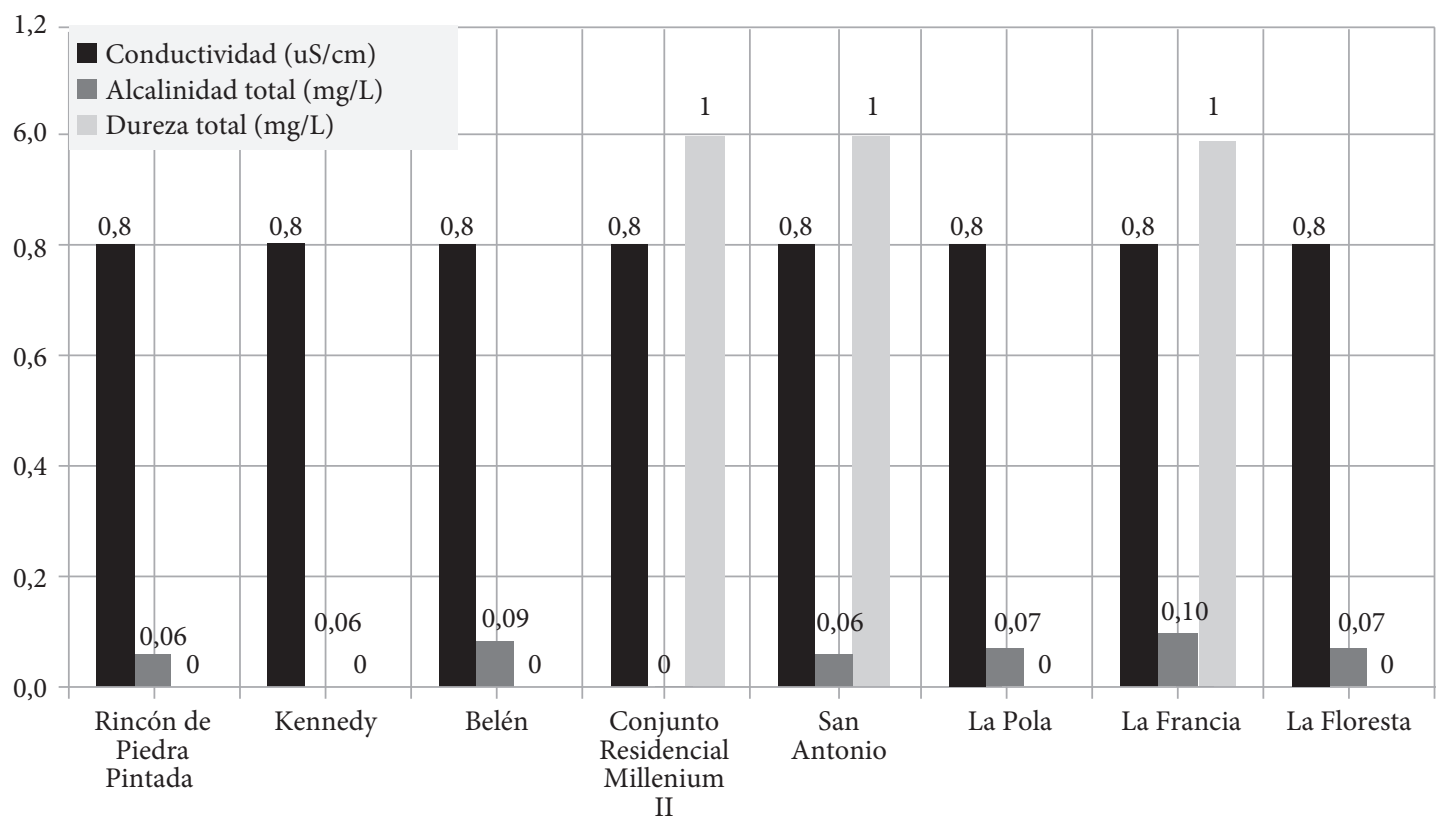

Figura 12. Resultados de cloruros, hierro total y sulfatos del agua lluvia en 8 puntos de muestreo de Ibagué Fuente: elaboración propia

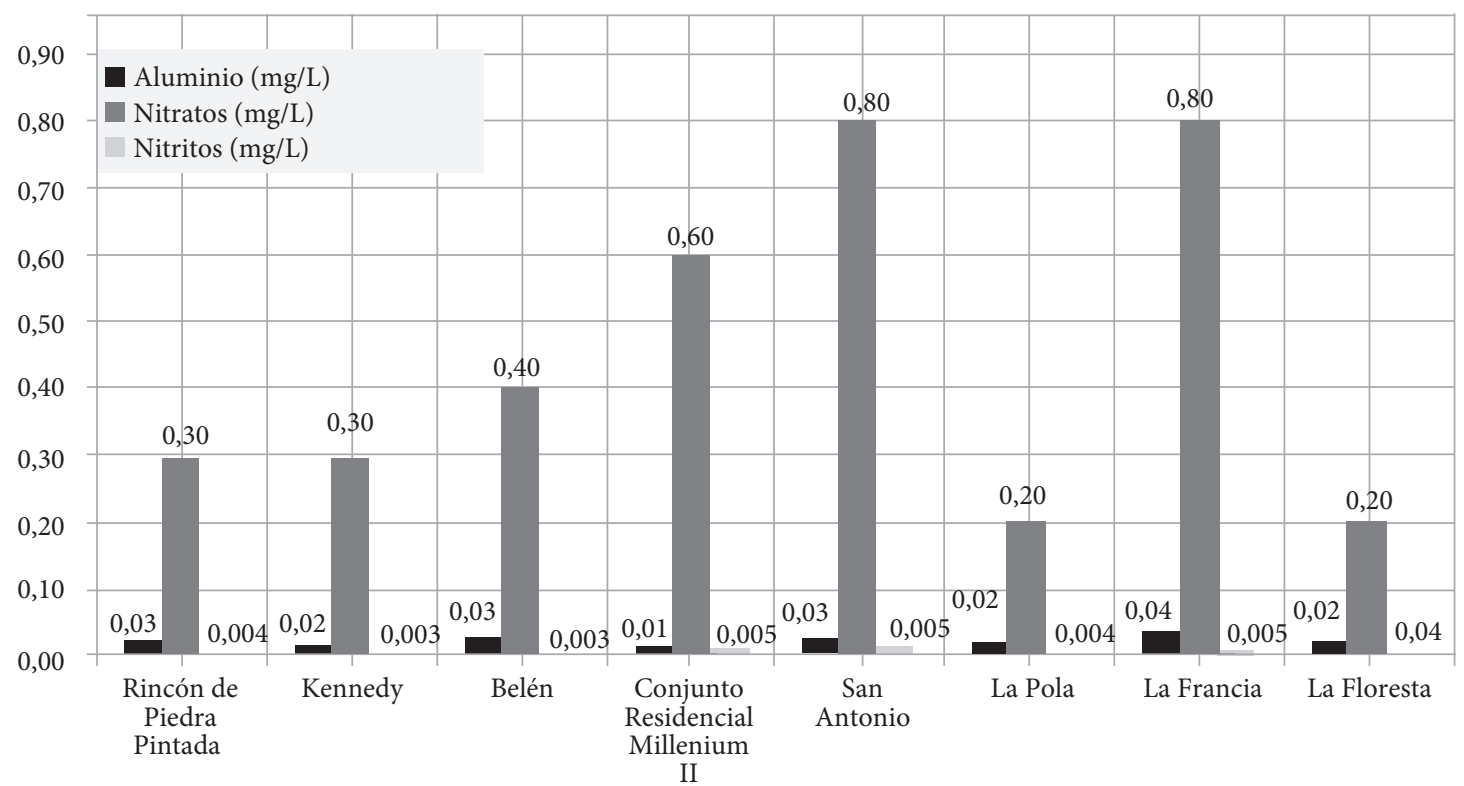

Figura 13. Resultados de aluminio, nitratos y nitritos de agua lluvia en 8 puntos de muestreo de Ibagué Fuente: Elaboración propia 


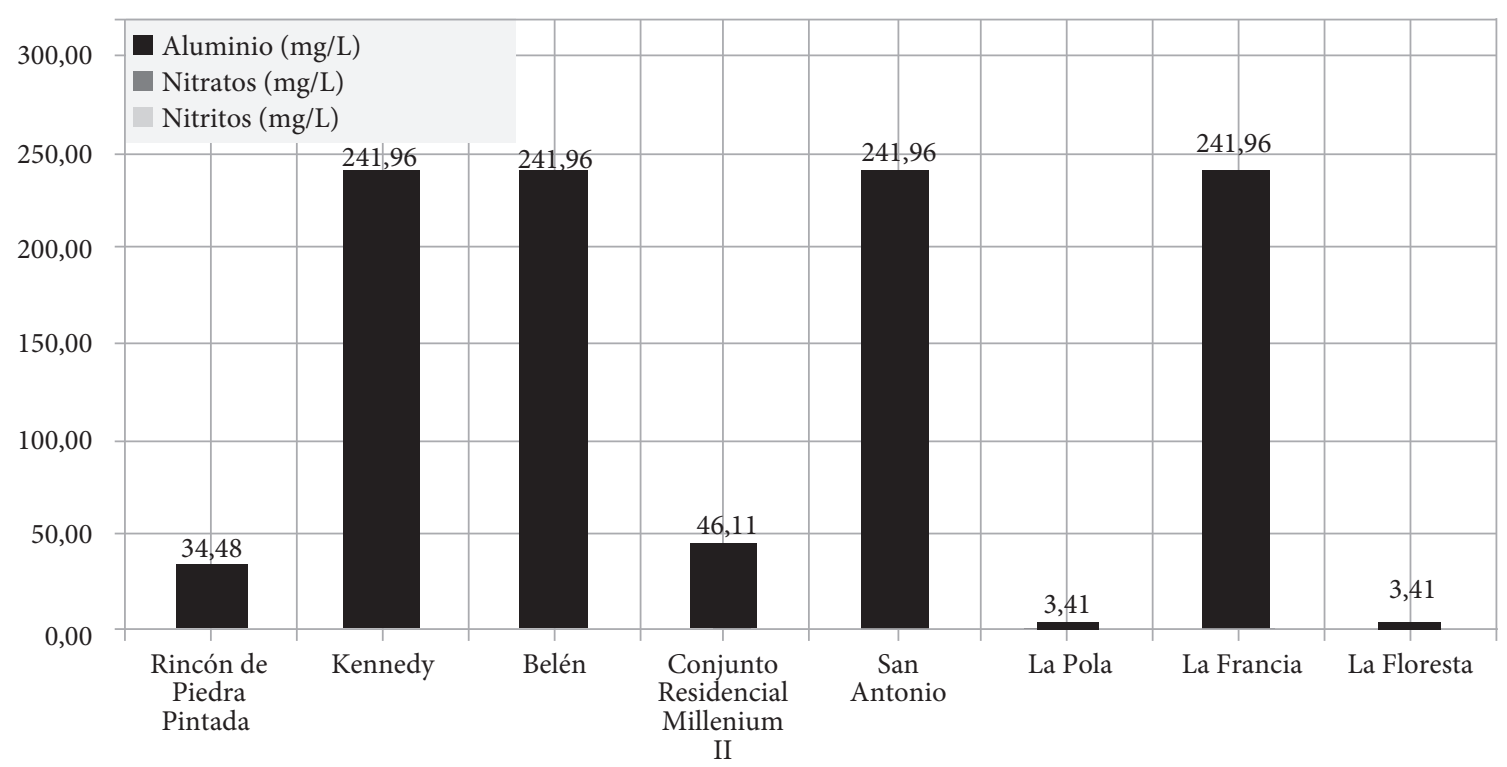

Figura 14. Resultados de coliformes totales de agua lluvia en 8 puntos de muestreo de Ibagué Fuente: Elaboración propia

Tabla 3. Resultados obtenidos de calidad de agua lluvia

\begin{tabular}{|c|c|c|c|c|c|c|c|c|c|c|c|c|c|}
\hline \multirow[t]{2}{*}{ PARÁMETRO } & \multirow[t]{2}{*}{ UNIDAD } & \multicolumn{2}{|c|}{$\begin{array}{l}\text { VALOR MÁXIMO } \\
\text { PERMISIBLE }\end{array}$} & \multicolumn{8}{|c|}{ VALORES OBTENIDOS (PUNTOS DE MUESTREO) } & \multirow{2}{*}{$\begin{array}{l}\text { CUMPLE/ } \\
\text { NO } \\
\text { CUMPLE }\end{array}$} & \multirow{2}{*}{$\begin{array}{c}\text { TRATAMIENTO } \\
\text { REQUERIDO }\end{array}$} \\
\hline & & $\begin{array}{c}\text { DECRETO } \\
1594 \mathrm{DE} \\
1984\end{array}$ & $\begin{array}{c}\text { RESOLUCIÓN } \\
2115 \text { DE } 2007\end{array}$ & 1 & 2 & 3 & 4 & 5 & 6 & 7 & 8 & & \\
\hline Turbiedad & UTN & & 2 & 1,92 & 0,70 & 2,70 & 1,76 & 4,22 & 2,76 & 2,76 & 1,00 & No cumplen & $\begin{array}{l}\text { Filtración } \\
\text { convencional }\end{array}$ \\
\hline Color aparente & UPC & 75 & 15 & 4,00 & 1,00 & 10,00 & 24,00 & 14,00 & 4,00 & 5,00 & 1,00 & Cumplen & $\begin{array}{l}\text { Filtración } \\
\text { convencional }\end{array}$ \\
\hline $\mathrm{pH}$ & & Entre 5 y 9 & Entre 6,5 y 9 & 7,35 & 6,47 & 5,48 & 4,98 & 4,93 & 6,28 & 4,74 & 5,63 & No cumplen & Neutralización \\
\hline Conductividad & Microsiemens $/ \mathrm{cm}$ & & 1000 & 17,20 & 11,40 & 6,00 & 9,70 & 16,00 & 0,00 & 15,00 & 0,00 & \multirow[t]{9}{*}{ Cumplen } & \multirow[t]{9}{*}{ No requiere } \\
\hline Alcalinidad & $\mathrm{mg} / \mathrm{l}$ & & 200 & 5,00 & 0,00 & 1,00 & 0,00 & 4,00 & 1,00 & 0,00 & 1,00 & & \\
\hline Cloruros & $\mathrm{mg} / \mathrm{l}$ & 250 & 250 & 15,00 & 17,00 & 14,00 & 10,00 & 12,00 & 8,00 & 6,00 & 8,00 & & \\
\hline Dureza total & $\mathrm{mg} / \mathrm{l}$ & & 300 & 0,80 & 0,80 & 0,80 & 0,80 & 0,80 & 0,80 & 0,80 & 0,80 & & \\
\hline Hierro total & $\mathrm{mg} / \mathrm{l}$ & & 0,3 & 0,06 & 0,06 & 0,09 & 0,09 & 0,06 & 0,07 & 0,10 & 0,07 & & \\
\hline Sulfatos & $\mathrm{mg} / \mathrm{l}$ & 300 & 250 & 0,00 & 0,00 & 0,00 & 1,00 & 1,00 & 0,00 & 1,00 & 0,00 & & \\
\hline Nitratos & $\mathrm{mg} / \mathrm{l}$ & 10 & 10 & 0,30 & 0,30 & 0,40 & 0,60 & 0,80 & 0,20 & 0,80 & 0,20 & & \\
\hline Nitritos & $\mathrm{mg} / \mathrm{l}$ & 10 & 0,1 & & 0,00 & 0,00 & 0,01 & 0,01 & 0,00 & 0,01 & 0,00 & & \\
\hline Aluminio & $\mathrm{mg} / \mathrm{l}$ & & 0,2 & 0,03 & 0,02 & 0,03 & 0,01 & 0,03 & 0,02 & 0,04 & 0,02 & & \\
\hline $\begin{array}{l}\text { Coliformes } \\
\text { totales }\end{array}$ & $\begin{array}{l}\text { microorganismos/ } \\
100 \mathrm{ml}\end{array}$ & 20000 & $\begin{array}{l}\text { No debe } \\
\text { contener }\end{array}$ & 34,48 & 241,96 & 241,96 & 44,11 & 241,96 & 3,41 & 241,96 & 3,41 & No cumple & Desinfección \\
\hline
\end{tabular}

Fuente: elaboración propia

El monitoreo del agua lluvia se ha utilizado como un indicador de la incidencia de actividades antrópicas sobre la calidad del aire [17], que para el caso de Ibagué, donde se obtuvieron algunos puntos de muestreo con valores de pн definidos como lluvia ligeramente ácida, se determinaron los potenciales agentes contaminantes a partir de la ubicación de las fuentes antropogénicas y la dirección de los vientos, ya que estas pueden 
incidir en el arrastre de polucionantes a ciertos lugares del perímetro urbano dependiendo de su dirección. De acuerdo con el IDEAM, la distribución porcentual de la dirección de los vientos en Ibagué tiene un ma- yor porcentaje en sentido Sur (17\%), Sur-Este (15\%), Este (14\%) y Oeste (12\%), como se describe en la Rosa de Vientos de la ciudad de Ibagué en la figura 15 [20].

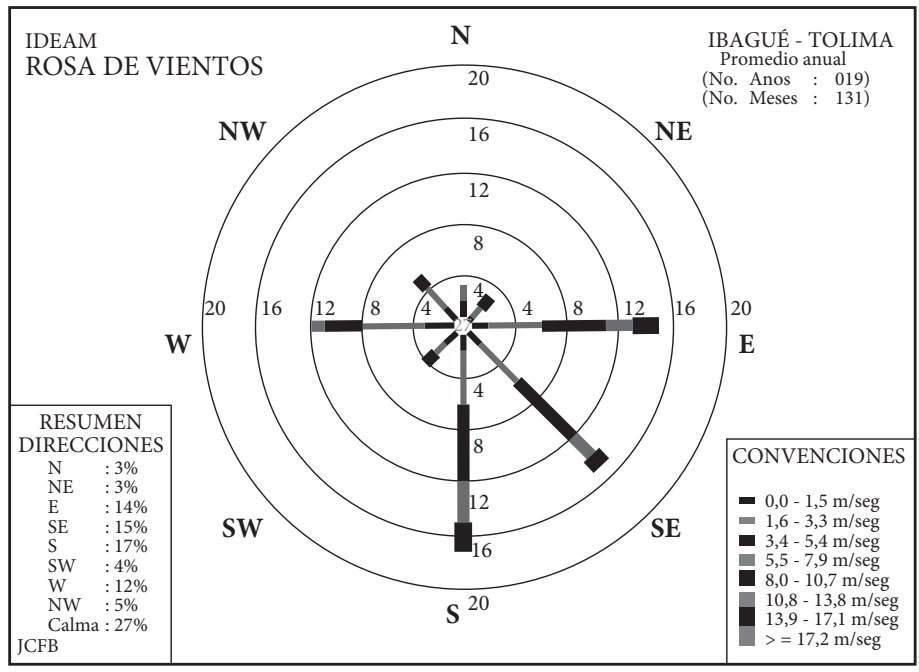

Figura 15. Rosa de Vientos de Ibagué

Fuente: [20]

La quema de combustibles fósiles realizada en diferentes actividades económicas generan gases considerados como contaminantes primarios, o sea, óxidos de azufre y nitrógeno, que al ser oxidados se convierten en contaminantes secundarios, característicos por ser más reactivos con el agua. En Ibagué, se tiene tres fuentes potenciales de contaminación del agua lluvia proveniente de los efluentes gaseosos de la industria, la minería y el transporte urbano. La zona industrial está localizada en la zona Sur-oriental del casco urbano, según se indica en la figura 8 , que corresponde al área perimetral de la vía Mirolindo que une a la ciudad de Ibagué con la vía nacional hacia Bogotá. Las actividades industriales presentes corresponden a fábricas de concreto, trituradoras de materiales de construcción, procesadoras de café y arroz, textileras y otras. Las emisiones gaseosas generadas en la zona industrial son en general transportadas fuera del perímetro urbano de Ibagué, dada la prevalencia de la dirección de los vientos, por lo que no se considera como el factor antropogénico más significativo en la contaminación del agua de lluvia.

El transporte público urbano es cubierto por buses y automóviles (taxis), que preferentemente utilizan diésel y gas como combustible, siendo usada la gasolina por el transporte particular. Las emisiones gaseosas originadas contribuyen con la contaminación del aire y del agua lluvia, siendo el principal factor antropogénico presente en la ciudad. La minería a cielo abierto es una actividad existente en la zona norte del casco urbano de Ibagué, como se describe en la figura 8, donde se explotan feldespatos y materiales para agregados de concretos que por efecto de la dirección prevalente de los vientos, concurren sus efluentes gaseosos al perímetro urbano con potencial contaminación del aire y del agua lluvia.

\section{Conclusiones y recomendaciones}

El agua lluvia en la ciudad de Ibagué es una potencial fuente alternativa de abastecimiento para consumo humano, especialmente cuando se deteriora la calidad del agua del río Combeima por elevados niveles de turbiedad, que obliga a la suspensión del servicio. Los criterios de calidad admisibles para la destinación del agua para recurso humano y doméstico que indican que para su potabilización se requiere solamente tratamiento convencional, relacionados en el Decreto 1594 de 1984 [18], se cumplen en su totalidad por las muestras tomadas en las ocho estaciones, de acuerdo con los indicadores 
evaluados. Su composición física, química y microbiológica permite su potabilización mediante tratamiento convencional, cumpliendo los requerimientos establecidos en la norma colombiana [19].

Los valores de $\mathrm{pH}$ obtenidos en algunos puntos de muestreo evidenciaron lluvia ligeramente ácida. La exposición a este tipo de lluvia puede ocasionar afecciones a los ojos, la piel y la pérdida del pelo [17]. El tratamiento convencional requerido para potabilizar el agua lluvia, comprende básicamente la aplicación de una solución de neutralización del pH con carbonato de sodio u otro, filtración para remover la turbiedad y desinfección para los coliformes totales. No se requiere realizar ningún proceso de clarificación, ni es necesario el uso de coagulantes y unidades de floculación-sedimentación, simplificando el proceso.

Los resultados de este estudio son preliminares, pero sugieren que la viabilidad técnica y económica del potencial aprovechamiento de las aguas lluvias como alternativa para uso doméstico, implica evaluar el aporte en cantidad que pueda captarse en soluciones familiares individuales o colectivas en la ciudad. La captación del agua lluvia implica el contacto de esta con diferentes superficies, como cubiertas, suelo, vegetación, zonas duras y otras, modificando las condiciones iniciales de calidad que requieren ser evaluadas para determinar el nivel de afectación que podría tener y que repercute en el tratamiento final requerido para su potabilización.

Los resultados obtenidos de pH por el IDEAM para el período 2001 a 2006 en Ibagué, tomados en una estación localizada en la zona central del perímetro urbano (calle 19 con carrera 7, barrio Interlaken) oscilan entre 4,5 y 7 unidades [14] que concuerdan con los obtenidos en el estudio realizado en el 2012, con valores entre 4,75 y 7,35 unidades [21], lo cual indica una característica permanente de ligera acidez en el agua lluvia, siendo factor de control permanente para su neutralización, en el evento de ser usada para consumo humano.

\section{Referencias}

[1] Sociedad Geográfica de Colombia, Mapa: división político-administrativa del Tolima, 2014. [En línea]. Disponible en: http://www.sogeocol.edu.co/dptos/tolima_05_division.jpg

[2] Comisión Europea, Agua para la vida, Luxemburgo: Oficina de Publicaciones Oficiales de las Comunidades Europeas, 2004, p. 13.
[3] Programa de las Naciones Unidas para el Desarrollo (PNUD), Informe sobre desarrollo humano, Nueva York, EE.UU., 2006.

[4] Programa de Medio Ambiente de Naciones Unidas (PNUMA), Geo, América Latina y el Caribe: Perspectivas del Medio Ambiente. México, 2003.

[5] Superintendencia de Servicios Públicos, Estudio Sectorial Acueducto y Alcantarillado 2006-2009. Colombia, 2010.

[6] Defensoría del Pueblo, Informe defensorial No 39 - B Diagnóstico sobre Calidad de Agua para Consumo Humano. Colombia, 2006.

[7] Defensoría del Pueblo, Derecho humano al agua - Clasificación municipal de la provisión de Agua en Colombia. Colombia, 2009.

[8] Ministerio de Ambiente, Vivienda y Desarrollo Territorial. Plan Departamental para el Manejo Empresarial de los Servicios de Agua y Saneamiento: Departamento del Tolima. Serie: n. ${ }^{\circ}$ 29, CDD: 352.14, 2010.

[9] Empresa Ibaguereña de Acueducto y Alcantarillado IBAL S.A. E.S.P. OFICIAL, Futuro y realidad del recurso hídrico en la ciudad de Ibagué. [En línea]. Disponible en: http:// www.ibal.gov.co/ARCHIVOS\%20TALLER\%20PDF/ ING_CARLOS_JOSE_CORRAL_ALBARELLO.pdf. Última consulta: febrero, 26, 2014.

[10] M. Vanegas. Estudio complementario del caso Ibagué. Colombia: Centro Panamericano de Ingeniería Sanitaria y Ciencias del Ambiente. 2002.

[11] Instituto de Hidrología, Meteorología y Estudios Ambientales - IDEAM, Cartas climatológicas medias mensuales. Precipitación. [En línea]. Disponible en: http:// bart.ideam.gov.co/images/precipitacion/preibague.gif. Última consulta: febrero, 26, 2014.

[12] Instituto de Hidrología, Meteorología y Estudios Ambientales (IDEAM), Precipitación en la ciudad de Ibagué de acuerdo a las medias mensuales de las cartas climatológicas. [En línea]. Disponible en: http://bart.ideam. gov.co/images/precipitacion/preibague.gif

[13] J. Montt, P. Rivera, B. Fernández, R. Valenzuela, “Caracterización de la calidad de las aguas lluvias urbanas de Santiago", Presentado en el XVI Congreso Chileno de Ingeniería Hidráulica. Sociedad Chilena de Ingeniería Hidráulica. Santiago, noviembre de 2003.

[14] C. Pérez, et al., "Análisis físico-químico del agua de lluvia en Buenos Aires y condiciones meteorológicas asociadas", presentado en el Congreso Argentino de Meteorología (11: 28, mayo - 21, junio: Mendoza, Argentina). Trabajos. Buenos Aires: FCEN, UBA; Conicet, 2012, pp. 1-5.

[15] A. Torres, et al., "Evaluación preliminar de la calidad de la escorrentía pluvial sobre tejados para su posible aprovechamiento en zonas periurbanas de Bogotá", 
U.D.C.A. Actualidad y divulgación científica, vol. 14, n. ${ }^{\circ}$, junio 2011. pp. 127-135. [En línea]. Disponible en: http://www.scielo.org.co/scielo.php?script=sci_ arttext\&pid=S0123-42262011000100016\&lng=pt\&nr $\mathrm{m}=$ iso. ISSN: 0123-4226.

[16] Instituto de Hidrología, Meteorología y Estudios Ambientales (IDEAM), La química de la lluvia ácida. [En línea]. Disponible en: http://institucional.ideam.gov. $\mathrm{co} / \mathrm{jsp} / 83$

[17] Instituto de Hidrología, Meteorología y Estudios Ambientales (IDEAM), "Estado y cambio del agua lluvia en Colombia", Informe anual sobre el estado del medio ambiente y los recursos naturales renovables en Colombia. Calidad del aire. [En línea]. Disponible en: http://documentacion.ideam.gov.co/openbiblio/Bvirtual/020650/ CalidaddelAireCapitulo5.pdf

[18] Ministerio de Agricultura (1984, junio 26) Decreto 1594 de 1984. Por el cual se reglamenta parcialmente el Título I de la Ley 9 de 1979, así como el Capítulo II del Título
VI -Parte III-Libro II y el Título III de la Parte III -Libro I- del Decreto - Ley 2811 de 1974 en cuanto a usos del agua y residuos líquidos. Bogotá, Colombia.

[19] Ministerio de la Protección Social y de Ambiente, Vivienda y Desarrollo Territorial, Resolución 2115 de 2007 Por medio de la cual se señalan características, instrumentos básicos y frecuencias del sistema de control y vigilancia para la calidad del agua para consumo humano. Bogotá, Colombia. [En línea]. Disponible en: http:// www.alcaldiabogota.gov.co/sisjur/normas/Norma1. jsp? $\mathrm{i}=30008$

[20] Instituto de Hidrología, Meteorología y Estudios Ambientales (IDEAM), Rosa de Vientos. [En línea]. Disponible en: http://bart.ideam.gov.co/images/vientos/ vienibague.gif. Última consulta: febrero, 26, 2014.

[21] C. Carvajal, et al., "Caracterización de las aguas lluvias de la ciudad de Ibagué para su aprovechamiento", Tesis de pre-grado. Ibagué: Universidad Cooperativa de Colombia, 2012. 